\title{
Aversion to inequality in Italy and its determinants
}

\author{
VINCENZO ATELLA ${ }^{1}$, JAY COGGINS ${ }^{2}$ and FEDERICO PERALI ${ }^{3}$ \\ ${ }^{1}$ Department of Economics, University of Rome Tor Vergata, Italy \\ ${ }^{2}$ Department of Applied Economics, University of Minnesota, USA \\ ${ }^{3}$ Department of Economics, University of Verona, Italy
}

\begin{abstract}
The main goal of this paper is to estimate the preferences of the Italian society towards equity in order to verify whether preferences (i) have changed across the years, and (ii) can be related to specific socio-demographic characteristics. Introducing equity concerns in the implementation of economic policies is a fundamental problem faced by both economists and policy makers. This paper uses a social welfare function à la Jorgenson and Slesnick to estimate society's aversion towards inequality by implementing a voting scheme for compiling individuals' equity preferences into a social choice by majority rule. The results show that preferences are highly polarized toward a low and a high concern for equity aversion and that this concern is significantly related with several sociodemographic characteristics. Among them, income plays an important role with richer people tending to favor less equity. Results also show that preferences towards equity have changed across the years.
\end{abstract}

Key words: inequality, majority rule, social welfare function, voting scheme.

\section{Introduction}

The main goal of this paper is to estimate the preferences of the Italian society towards equity in order (i) to measure the degree of aversion towards inequality in the Italian society in the period 1985-1996 and (ii) to verify whether and how preferences have changed across the years. For eliciting preferences towards equity we use a social welfare function of the form introduced by Roberts [39] and empirically implemented by Jorgenson and Slesnick [30, 31] and Jorgenson [28]. We estimate society's aversion towards inequality by implementing a voting scheme for compiling individuals' equity preferences into a social choice by majority rule. ${ }^{1}$

The social welfare function of Italian households is estimated from the aggregation of individual preferences derived from demand estimates based on a 12-year time series of cross-sections, ranging from 1985 to 1996.

We elicitate social preferences concerning equity by designing a scheme that gives a hypothetical social observer the mandate to determine the price policy that optimizes the social welfare function, conditional on different choices of the coefficient $\rho$ governing the curvature of the social welfare function - thus capturing society's degree of aversion to inequality.

We then hypothesize the existence of a super partes social observer, personified by a benevolent computer, who computes the individual levels of welfare, obtained 
from the household budget data of each Italian household, associated with each price policy. Households cast their vote by "truthfully" revealing their most preferred price policy and, indirectly, preferred value for $\rho$. The unique winner of the voting scheme is the median voter who reveals society's preferences towards inequality.

In our simulated poll every member of society votes rationally, compatibly with personal incentives. Individuals in our model do not regard others altruistically. Rather, they consider only their own selfish interests when voting for equity. Households that would benefit under a policy regime that weights equity heavily prefer such a weighting and will vote for it, thus revealing the "single peaked" individual preferences towards aversion to inequality associated with the preferred prices. The majority rule will then give the elections' winner, that is the society's degree of aversion to inequality.

According to our empirical results, we find that Italian preferences are polarized around a "low" and a "high" degree of aversion to inequality and that this concern is strongly related with several sociodemographic characteristics. As expected, income is an important factor and richer households are less concerned about equity. In general, preferences towards equity have changed substantially across the years. By majority rule, Italian society prefers a "high" degree of aversion to inequality over the entire period of investigation with the exception of the years 1990 and 1995.

The paper is organized as follows. Section 2 describes aggregate measures of inequality and poverty in Italy from 1985 to 1996 to gain some notion about possible changes in the level of tolerance of Italians towards inequality and poverty. Section 3 introduces the concepts of equity, interpersonal comparisons and social welfare. Sections 4 through 6 present the methodological framework used to derive the distribution of $\rho$ and implement the voting scheme. Section 7 describes the data set used. Section 8 reports the empirical results from the system of demand equations used to estimate the individual and social preferences along with the mechanism design used to elicit the collective preferences concerning the degree of Italians' aversion towards inequality. Section 9 presents the regression results analyzing the influence of demographic characteristics over the choice of $\rho$ with the aim of characterizing the voter profile. Section 10 presents our conclusive remarks.

\section{Inequality and poverty in Italy from 1985 to 1996}

The period under examination has been characterized by a series of substantial social, economic, political and institutional events that may have changed the subjective perception of the Italian citizen and society about inequality at different points in time. In this section, we present a concise analysis of these events and make a conjecture about how they may have influenced households' economic behavior and the personal and social level of tolerance towards inequality. 


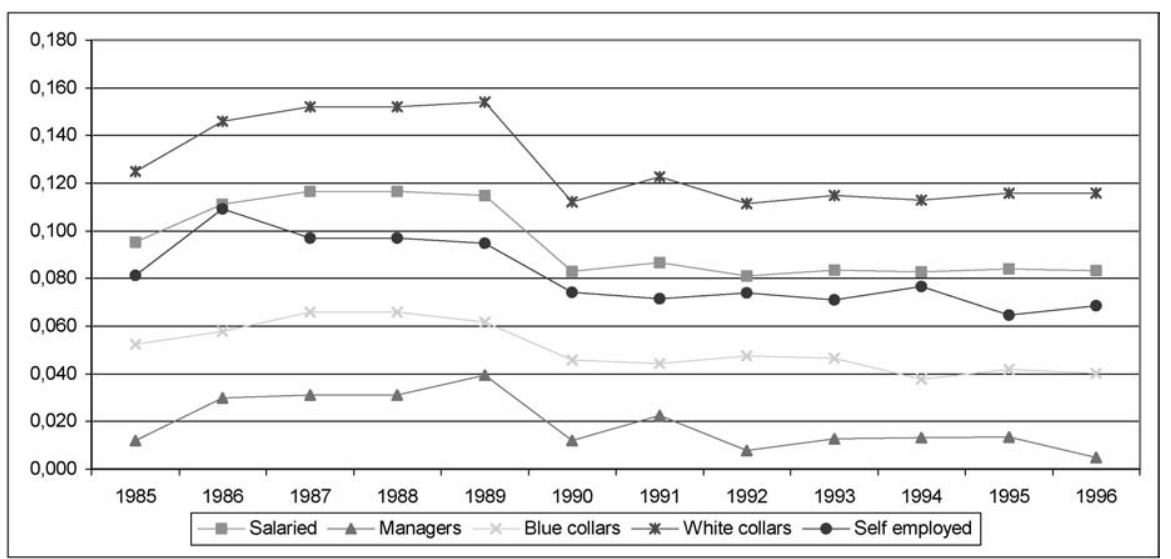

Source: Our calculation is based on Bank of Italy data

Figure 1. Head count ratios.

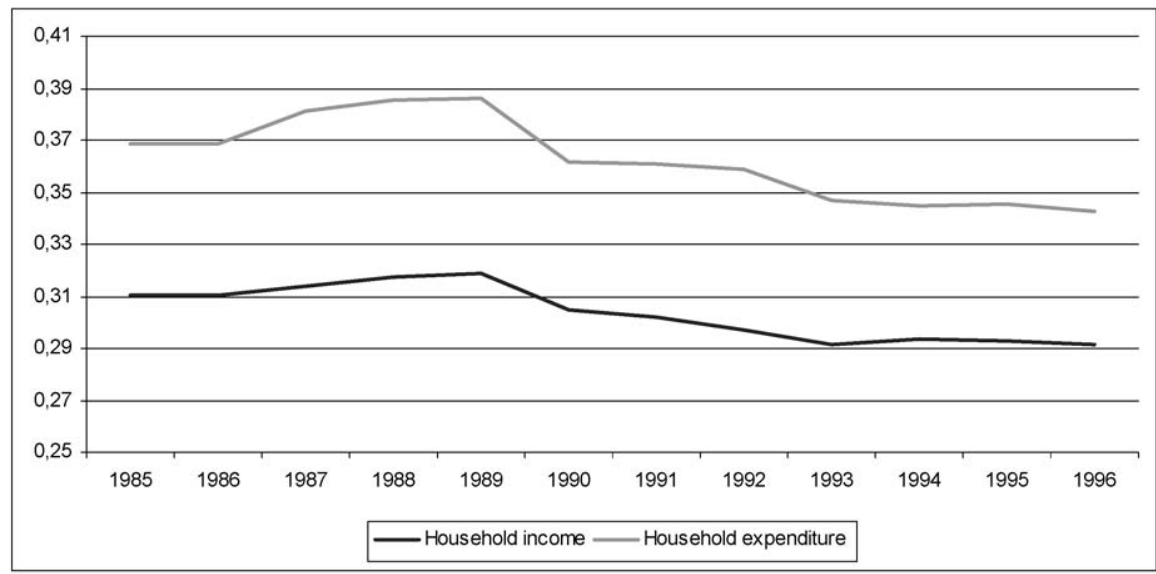

Source: Our calculation is based on Bank of Italy data

Figure 2. Evolution of Gini coefficients.

It is widely recognized that during the last two decades income inequality has increased in all industrialized countries. The international variability of income distribution has increased as well. According to Atkinson et al. [7] and Fritzell [23] this situation has been determined by the social and economic policies implemented by single states over this period. These policies, and in particular wage and employment policies, have reduced the share of labour income over total income and increased inequality in labour income. Further, the paucity of transfer payments, such as child benefits, and tight fiscal and social reforms have exacerbated such inequalities.

In the case of Italy, during the 1980s policy makers coherently implemented economic and social policies which led to a slight increase in income inequality, despite the prolonged period of economic expansion experienced at the end of the 
Table I. Contribution to the rate of growth of household permanent disposable income (\%)

\begin{tabular}{llllr}
\hline & $1970: 1$ & $1981: 1$ & $1989: 1$ & $1993: 1$ \\
& $1980: 4$ & $1988: 4$ & $1992: 4$ & $1998: 4$ \\
\hline Social contribution (-) & 21.1 & 17.2 & 18.7 & 21.5 \\
Direct tax (-) & 29.2 & 27.7 & 26.6 & 43.1 \\
Interest paid by the P.A. (+) & 21.5 & 26.0 & 34.4 & -24.2 \\
Government transfers (+) & 34.8 & 39.4 & 41.9 & 40.6 \\
Other incomes (rents, financial, etc.) (+) & 13.1 & 32.7 & 32.5 & 130.0 \\
Labor income (+) & 84.9 & 47.5 & 34.9 & 23.8 \\
\hline
\end{tabular}

Source: Atella [5].

'80s [42]. However, the difficult international economic conditions and the restrictive budgetary policies adopted to meet the Maastricht requirements in the early '90s did not significantly affect the distributive situation. For the period 19851996 under investigation, Figures 1 and 2 show the changes in poverty levels by employment category, as reflected by the head-count ratio, and in the levels of the Gini coefficients respectively. ${ }^{2}$ The head-count ratios and Gini coefficients, computed on the basis of both household incomes and total expenditures, move in a similar fashion. Both series step down between 1989 and 1990 and maintain the same level thereafter. This result is not surprising if we consider that the fiscal adjustment process that started in 1992 was probably not worse than the disruptive distributive dynamics recorded during the '80s. Ex-post, the facts which occurred during the second half of the ' 80 s can easily be considered as a "missed opportunity" to implement economic and social policies aimed at reducing poverty and inequality levels.

At the end of 1994 when the risk of financial bankruptcy incurred by the Italian public financial administration was over, social and economic policies shifted in the direction of achieving greater efficiency in order to achieve a higher level of competitiveness and economic growth. According to Rossi [43] and Atella [5], this process was carried out without affecting the goals of social justice.

The events which occurred during the twelve years of our investigation strongly influenced household disposable incomes in terms of both levels and composition. The graph in Figure 3 illustrates the rate of growth of the real permanent disposable income $^{3}$ of Italian households from 1970 to 1999. From this graph we can see that rates of growth increased during the ' 80 s and decreased sharply in the first half of the '90s, while they remained constant, though at a low level, in the second half. In Table I we report the contribution of the individual components to the disposable income. The data show a sharp change over time in the importance of the individual components determining the rate of growth of disposable income. In particular, one can observe that the rate of growth of direct taxes increased substantially across the 


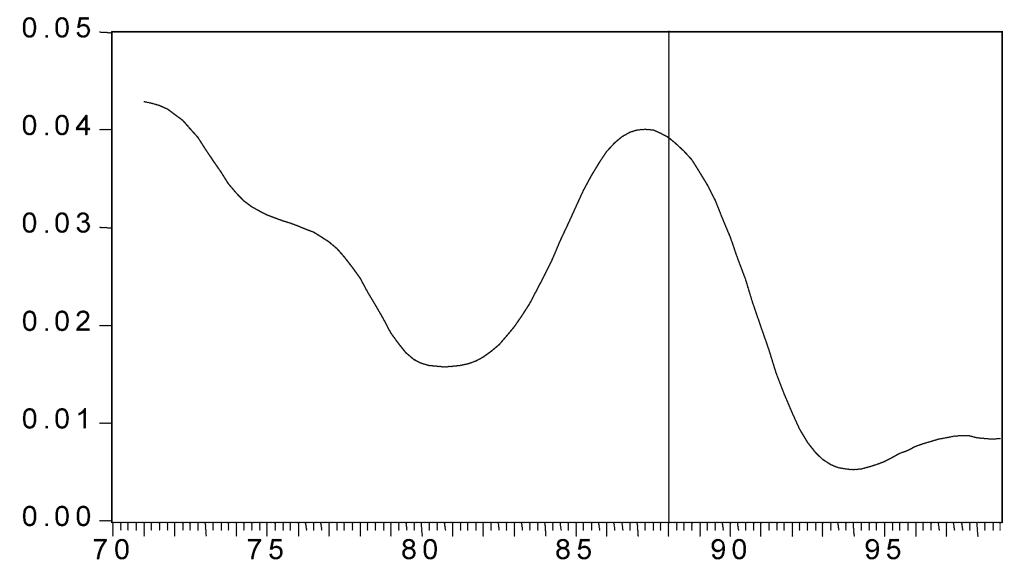

Source: Atella [5]

Figure 3. Rates of growth of the permanent disposable income permanente.

years determining a sharp reduction in disposable income. At the same time, the rate of growth in interest paid by the Public Administration for the public debt decreased, especially after 1988, while the component "other incomes" increased. This change is mainly attributable to the large shift of Italian households from the bond to the equity market due to the sharp fall of interest rates in the '90s. Finally, labour income also decreased in importance over time. During the ' 70 s, it represented 85 percent of the rate of growth of disposable income, while at the end of the '90s it accounted for only 24 percent.

In our view, the changes in the composition of household disposable income rates of growth which occurred during these years may also reflect a change in the attitude of Italian households towards equity. Intuitively, given the relative stability of aggregate inequality and poverty throughout the period under consideration, one may suspect that the degree of aversion towards inequality was also stable. To evaluate this conjecture, we use a novel mechanism to elicit social preferences about equity, described in the following sections.

\section{Equity, interpersonal comparisons and social welfare}

How much weight should be given to equity concerns in policymaking? Economic analysis often focuses on Pareto efficiency. One of the appealing features of the Pareto criterion is that it requires neither a cardinal utility measure nor interpersonal comparisons of utility. But this criterion yields only a partial ordering: in a given setting many alternatives will be efficient and the criterion gives no guidance about which of them should be chosen. An equity-based criterion might go further, delivering a unique policy recommendation that optimally redistributes welfare across members of a society. 
In this paper we make use of an equity-based social welfare function (SWF) which requires the imposition of cardinality and interpersonal comparability conditions. Each possible individual utility function has specific properties of measurability that impose restrictions on the informational basis available to the ethical observer. The set of all possible utility functions can be partitioned into information invariance classes that describe the degree of measurability and comparability being assumed [20,40]. A comparison of utility levels between individual $i$ and $j$ is a statement that establishes a rank between the levels $u_{i} \succeq u_{j}$ of the utility functions $U_{i} \succeq U_{j}$ of person $i$ and person $j$ [26]. Consider a change of social state, described by the transition from an allocation $\bar{x}=\left(\bar{x}^{1}, \ldots, \bar{x}^{K}\right) \in X$ to an allocation $\widehat{x}=\left(\widehat{x}^{1}, \ldots, \widehat{x}^{K}\right) \in X$ also included in the set of all social states $x$ with $k=1, \ldots, K$ elements, that may be ranked by a social welfare functional. Define a social welfare functional as a mapping from the set of all possible realvalued individual welfare functions, defined on the set of social states $W^{K}(X)$ and including the set of all admissible utility profiles, to the set of all possible social orderings $\Re(X), W: W^{K}(X) \rightarrow \Re(X)$. The social preference ordering that is obtained by applying $W$ to some $W^{K}(X)$ is denoted by $R$, or by $P$ for strict preference and $I$ for an indifference relation. The properties of unrestricted domain $(U)$, independence of irrelevant alternatives $(I)$, and the weak Pareto $(P)$ principle ensure that the only information used by the social welfare function $W$ in ranking two alternatives are the utilities attained in the two states, so that it is possible to establish an ordering $W(U(\bar{x}, d)) R W(U(\widehat{x}, d))$ between social states. These properties, along with ordinal noncomparability of the utility profile, admit only a dictatorial social ordering by Arrow's Impossibility Theorem [4]. D'Aspremont and Gevers [20] and Roberts [39, 40] showed that a class of social orderings can be obtained by extending the informational basis to cardinal unit comparability of the individual welfare functions and utility profiles. The same is true for cardinal and noncomparable [44] and for ordinal and comparable [40] individual utilities. By assuming both cardinality and interpersonal comparability, which together imply that a great deal is known about individual welfare orderings, a broad range of social welfare functions becomes available.

Welfare levels that are cardinal unit comparable cannot be ranked. However, it is possible to determine how a change in policy affects different individuals. Under cardinal unit comparability, the set of welfare functions yielding the same social ordering $\Re(X)$ must satisfy the condition:

$$
\Re(X)=\left\{W^{K}(X)=\alpha_{k}+\beta W_{k}(x), \beta>0\right\}
$$

which is invariant to positive affine transformations with respect to the scaling parameter $\beta$ that, as opposed to the shift parameter $\alpha_{k}$, is the same for all individuals. The conditions of Cardinal unit comparability and of anonymity [32], ensuring that the names of the individuals are irrelevant in establishing the weights given to each individual so that $W$ is symmetric, are sufficient to permit a utilitarian 
representation of the social welfare functional expressed as a weighted sum of welfare functions:

$$
\bar{x} R \widehat{x} \Leftrightarrow \sum_{k} \alpha_{k} W\left(U\left(\bar{x}, d_{k}\right)\right) \succeq \sum_{k} \alpha_{k} W\left(U\left(\widehat{x}, d_{k}\right)\right) .
$$

The utilitarian representation of the social welfare functional does not incorporate information about the distribution of welfare among the population. If it is assumed that both levels and changes of welfare are comparable, the invariance restrictions on the social welfare functional must be weakened in order to admit a larger set of feasible social welfare functionals. Roberts [40, Theorem 4] shows that if $W$ satisfies $(U),(I),(P)$ and cardinal full comparability (CFC) so that the set of social preference orderings $\Re(X)$,

$$
\Re(X)=\left\{W^{K}(X)=\alpha+\beta W_{k}(x), \beta>0\right\}
$$

is invariant to any positive affine transformations of the individual welfare function, then there exists a complete, reflexive and transitive linearly homogeneous function $g(x)$ of deviations of levels of individual welfare from the mean level of welfare, which transforms the social welfare functional as

$$
W(U(x, d))=\bar{W}(x)+g[U(x, d)-\bar{W}(x)], \quad \text { for } \bar{W}(x)=\sum_{k} \alpha_{k} W_{k}(x) .
$$

Under cardinal full comparability, social outcomes are ordered on the basis of the sum of the mean individual welfare level and a measure of dispersion of individual welfare levels describing the degree of inequality in its distribution. This social welfare functional describes how social judgments can be affected by the equity versus efficiency tradeoff. For example, if a notion of vertical equity is adopted, a more egalitarian distribution is preferred to a more dispersed one.

This representation of social preferences suffers an identification problem analogous to the problem of identifying equivalence scales $[15,35]$ at the level of individual preferences. If welfare and non-welfare information about alternative social states, such as libertarian rights, had a direct effect on $W(U(x))$ along with the indirect effect through the individual welfare functions $W_{k}$, then individual welfare levels would become ordinally noncomparable, and, thus, non-aggregable into a social welfare functional. This observation was first noted by Sen [45], who refers to this property as welfarism. Roberts [40] points out that the driving force confining non-welfare characteristics of social states to an irrelevant role in determining social orderings is the Pareto condition. By weakening $(P)$ with the principles of positive association $(P A)$ and non-imposition $(N I)$, Roberts proves the existence of a social welfare functional

$$
W(U(x, d))=F\{\bar{W}(x)+g[x, U(x, d)-\bar{W}(x)], x\},
$$

for $\bar{W}(x)=\sum_{k} \alpha_{k}(x) W_{k}(x)$ that incorporates non-welfare characteristics of social states through the weights $a_{k}(x)$, the linear homogeneous function $g(x)$, and through $F[\cdot, x]$ that depends directly on the social state $x$. 
This class of welfare functionals is exempted from the criticism of welfarism, but requires an informational basis often too large to make welfare judgments operational. What is crucial, as for individual utility profiles, is to contract the informational basis while maintaining the identifiability of social preference orderings. The informational constraint imposed on $F(x)$ being independent of $x$ is conceptually similar to that imposed at the individual level to permit household comparability. In order to obtain an operational social welfare function it is necessary to specify a functional form for $g(x)$ and for individual welfare functions $W_{k}(x)$. We follow Jorgenson and Slesnick's [32] and Slesnick's [48] choice for the function $g(x)$ and the set of weights $a_{k}(x)$. As required by cardinal full comparability (CFC), the class of individual welfare functions must be invariant with respect to affine transformations.

CFC permits great flexibility in the choice of a social welfare function. This is especially attractive for empirical work. Roberts [39] showed that under CFC one can always find a SWF, $W$, such that for any two social states $x$ and $y, W(U(x))>$ $W(U(y))$ if $x$ is strictly preferred to $y$ according to the social ordering, where $U$ is the vector of individual welfare orderings. If we let $\bar{U}(x)$ denote the average of individual utilities, then Roberts's SWF takes the form

$$
W(U(x))=\bar{U}(x)-g(U(x)),
$$

where $g$ measures the dispersion in individual welfare levels. According to this function, social welfare increases when average individual welfare increases, and falls when dispersion in individual welfare increases.

Even after one has decided to employ CFC utilities, incorporating equity concerns in an empirical setting remains challenging for at least three reasons. First, the CFC assumption must be operationalized in a way that leads to a meaningful money-metric measure of cardinal and comparable individual utilities. In practice, this can be accomplished by introducing demographic information in a plausible demand system. Actual income is scaled by an adult equivalence scale that accounts for the heterogeneous demographic makeup of households. Under certain conditions the resulting scaled income can play the role of a money-metric measure of utility.

Second, one has to select a specific functional form for the SWF, one that reflects a degree of aversion to inequality. We employ the SWF of Jorgenson [28] and Jorgenson and Slesnick [30, 31]. This SWF captures society's preferences towards inequality in elegant fashion through the use of a single "equity" parameter, $\rho$, describing the curvature of social indifference curves.

Third, one must choose a particular value for the degree of inequality $\rho$ in the SWF. Coggins and Perali [18] have shown that the choice of $\rho$ is critical because it significantly affects the curvature of the social welfare function and hence the associated policy and welfare analysis. In the literature, two main approaches to estimating social equity preferences can be found. The one described by Christiansen and Jensen [17] and Stern [50] involves deducing the level of equity preferences 
from government tax decisions. The approach presented in Amiel et al. [3] involves estimating aggregate equity preferences through experimental methods. The model presented in this paper represents a new approach to the problem.

\section{The methodological framework}

\subsection{INTERPERSONALLY COMPARABLE INDIVIDUAL WELFARE}

Suppose that a household obeys a direct utility function of the form $U^{*}\left(q_{k}\right)$, where $q_{k}$ denotes the $n$-vector of goods available at prices $p$ consumed by household $k$ $(k=1, \ldots, K)$. Corresponding to $U$ is a cost (or expenditure) function of the form $C^{*}(U, p)$, which yields the cost to the household of achieving utility level $U$ at prices $p$. Let $d_{k}$ denote a vector of demographic variables, such as household size, age, and level of education, specific to household $k$. Lewbel's modifying technique consists in defining a general cost function of the form $C\left(u, p, d_{k}\right)=$ $f\left(C^{*}\left(u, p, d_{k}\right), p, d_{k}\right)$. Lewbel [33] presents conditions that must be satisfied by $f$ in order for $C$ to be a legitimate cost function. ${ }^{4}$ Note that by construction $C$ will take the value of household income $y_{k}$.

The modifying function approach is a generalization of a variety of specific approaches to the problem of incorporating demographic information into a demand system. These include the translating and scaling approaches, the Gorman [25] approach that combines translating and scaling, and also reverse Gorman as developed in Pollak and Wales [37, 38]. The demographic specification used in this study is the Barten [8] approach.

Our aim in this paper is to use a measure of household welfare accompanying the cost function demographically modified à la Barten to compare the level of social welfare for various economic policies. For this purpose we shall need a household equivalence scale $m_{0}\left(p, d_{k}\right)$, depending on prices and demographic characteristics, that describes the number of equivalent adults in the household. This scale can be used to form a money measure of welfare that is comparable across households. A household's equivalent income is given by $y_{k} / m_{0}\left(p, d_{k}\right)$. If a two-adult household with an income of $\$ 60,000$ has $m_{0}=1.5$, for example, then each of its members achieves the same level of utility as a single adult with an income of $\$ 40,000$. Similarly, if a household with two adults and two children with income of $\$ 60,000$ has $m_{0}=3.0$, then each of its members achieves the same level of utility as a single adult with an income of $\$ 20,000$.

The scale $m_{0}$ can be written in this manner, without utility as an argument, only if it is independent of the base level of income (IB) chosen for comparison [34]. The IB property of equivalence scales permits interhousehold comparisons to be computed exactly [13].

Suppose that demand is specified as the Almost Ideal Demand System of Deaton and Muellbauer [21]. The Barten demographically modified AIDS cost function, expressed in logarithms, is 
$\ln C\left(u, p, d_{k}\right)=\ln A\left(p, d_{k}\right)+B\left(p, d_{k}\right) \ln u$.

This cost function is in the Gorman polar form [12], from which the AIDS is derived using the Barten-Gorman demographic transformation. In (2), the $\ln A$, and $B$ terms are expressions depending upon the parameters in a Barten demographically modified demand system

$$
\begin{aligned}
& \ln A\left(p, d_{k}\right)=\alpha_{0}+\sum_{i} \alpha_{i} \ln p_{i}^{*}+\frac{1}{2} \sum_{i} \sum_{j} \gamma_{i j} \ln p_{i}^{*} \ln p_{j}^{*}, \\
& B\left(p, d_{k}\right)=\beta_{0} \Pi_{i}\left(p_{i}^{*}\right)^{\beta_{i}},
\end{aligned}
$$

where $i=\{1, \ldots, n\}$ indexes the goods.

In Equations (3), $p_{i}^{*}=p_{i} m_{i}\left(d_{k}\right)$ is the price of good $i$ scaled by the Barten [8] commodity-specific scheme. The scaling demographic function is specified as $m_{i}\left(d_{k}\right)=\sum_{r} \delta_{i r} \ln d_{k}^{r}$. The parameters $\alpha_{i}, \beta_{i}$, and $\gamma_{i j}$, and also $\delta_{i r}$, are to be estimated using the following share demand system, derived from Equation (2) and Equations (3):

$$
w_{i k}=\alpha_{i k}+\sum_{j} \gamma_{i j} \ln p_{j}^{*}+\beta_{i} \ln \left(\frac{y_{k}^{*} P^{T}}{A\left(p^{*}\right)}\right)
$$

where $\ln y_{k}^{*}=\ln y_{k}$, and $P^{T}(p, d)=\Pi_{i} p_{i}^{t_{i}(d)}$ is the translating term representing fixed costs where demographic factors interact with prices. The demographic function includes a variable indexing time to control for the year effect of the time-series of cross-sections and demographic attributes specified linearly.

In order for the scale $m_{0}$ to be IB, it is necessary that the $B\left(p, d_{k}\right)$ term be independent of $d_{k}$. Let us suppose that it is. Then following Lewbel [34], write the modified cost function

$$
C\left(u, p, d_{k}\right)=m_{0}\left(p, d_{k}\right) G(p, u)
$$

for some function $G .^{5}$ The separability of $d_{k}$ from $u$ in the two terms on the right side of (5) makes the IB property convenient. In the demographically modified AIDS framework we may write

$$
\ln G_{k}(p, u)=\ln A(p)+B(p) \ln u,
$$

which, combined with (5), yields the following money metric of utility describing the distribution of welfare [34, 13]

$$
\ln \left(\frac{C}{m_{0}}\right)=\ln A(p)+B(p) \ln u .
$$

Equation (7) highlights an important feature of the interpersonally comparable nature of this setup. Note that everything specific to a household's preferences appears on the left hand; the right is an affine transformation of utility levels $u$. 
Thus, it accords with Roberts' [39] definition of cardinal full comparability (CFC) of utilities. ${ }^{6}$ Once again employing the notation of the Barten-Gorman demographically modified AIDS framework, the equivalence scale $m_{0}$ may be written in log form as

$$
\begin{aligned}
\ln m_{0}\left(p, d_{k}\right)= & \ln A\left(p, d_{k}\right) \\
= & \alpha_{0}+\sum_{i} \alpha \ln p_{i}^{*}+\frac{1}{2} \sum_{i} \sum_{j} \gamma_{i j} \ln p_{i}^{*} \ln p_{j}^{*}+ \\
& +\sum_{i} t_{i}\left(d_{k}\right) \ln p_{i}^{*} .
\end{aligned}
$$

Upon rearranging Equation (5), the indirect utility function for household $k$ may be written

$$
\ln V_{k}\left(y_{k}, p, d_{k}\right)=\frac{\ln \left(\frac{y_{k}}{m_{0}\left(p, d_{k}\right)}\right)-\ln A(p)}{B(p)},
$$

where by definition $y_{k}=C\left(V_{k}\left(y_{k}, p, d_{k}\right), p, d_{k}\right)$.

\section{Social welfare}

Suppose that the welfare of society is determined according to the following specific social welfare function taken from Jorgenson and Slesnick [30, 31] and Jorgenson [28, 29]. Let $U$ denote the $K$-dimensional vector of household utility levels, and let $x$ denote the state of the world. The social welfare function takes the form

$$
W(U, x \mid \rho)=\ln \bar{V}-\gamma(x)\left(\frac{\sum_{k} m_{0}\left(p, d_{k}\right)\left|\ln V_{k}-\ln \bar{V}\right|^{-\rho}}{\sum_{k} m_{0}\left(p, d_{k}\right)}\right)^{-1 / \rho},
$$

where

$$
\ln \bar{V}=\frac{\sum_{k} m_{0}\left(p, d_{k}\right) \ln V_{k}}{\sum_{k} m_{0}\left(p, d_{k}\right)},
$$

and

$$
\gamma(x)=\left[\frac{\sum_{k \neq j} m_{0}\left(p, d_{k}\right)}{\sum_{k} m_{0}\left(p, d_{k}\right)}\left(1+\left(\frac{\sum_{k \neq j} m_{0}\left(p, d_{k}\right)}{m_{0}\left(p, d_{j}\right)}\right)^{-(\rho+1)}\right)\right]^{1 / \rho},
$$

where $m_{0}\left(p, d_{j}\right)=\min _{k} m_{0}\left(p, d_{k}\right)$ is the scale for a reference household. In a time series application, like the one following, it is natural to let this reference household correspond to the household in period 1 .

The first term in (10) is the average of money metric welfare across households. The second term is a measure of dispersion (or inequality) in money metric welfare. For a given level of average welfare, social welfare declines as the inequality in 
welfare increases. The $\gamma(x)$ term in (10) is constructed so as to permit the highest possible value that satisfies the Pareto principle. It is conceivable, for general definitions of $\gamma(x)$, that social welfare might fall as a result of an increase in one household's welfare level. As $W$ is defined in (10), this cannot happen.

The parameter $\rho$ captures society's "degree of aversion to inequality" [28, p. 1025], which is the same thing as the degree of curvature of the welfare function in $\ln V$ space. It takes values on the interval $(-\infty,-1]$. If $\rho=-\infty$, then the second term in (10) disappears and the social welfare function becomes utilitarian. If $\rho$ takes its maximum value of -1 , then the second term in (10) will be equal to a weighted average of the distances of the household specific indirect utility functions from its weighted average. In this case, it turns out that society places the greatest possible value upon equity, by "correcting" the weighted average indirect utility function by the household specific levels of concern for equity. We turn now to a model of a social observer who is considering an economic policy that is designed to maximize $W$ given $\rho$, and the accompanying scheme for estimating the value for $\rho$ that actually reflects society's attitudes towards equity.

\subsection{VOTING FOR EQUITY}

In this section we develop a scheme for recovering society's preferences towards inequality from demand behavior and demographic characteristics. The informational assumptions placed upon the problem are crucial. It is assumed that the social observer does not know the structure of individual welfare functions. Rather, the observer knows only how to use the computer program managing the solution algorithm for $\rho$. This constraint on the social observer information set excludes any possibility of manipulation by the social observer and explains the observer's decision to collect the households' votes over $\rho$. Each household knows only its own cost function, and it is also privy to the information it needs in order to make its selection in the voting scheme. Let $\Omega_{k}$ denote the information held by household $k$. By assumption, households do not behave strategically while participating in the voting scheme.

The voting-for-equity scheme is recursive in nature, comprising two parts. For any given $\rho$, the observer's goal is to set prices so as to maximize social welfare $W(U, x \mid \rho)$. Price policies are not uncommon in actual practice, of course, though in a market economy one would not expect to witness centralized selection of a complete vector of prices. It would be possible to adapt the model by incorporating alternative policy instruments - including quantity restrictions or income transfers.

The first part, then, consists in the observer devising a table, each row of which corresponds to a value for $\rho$. The distance between $\rho$ 's may be as small as desired. The remaining entries in a row of the table consist of a price vector with the property that for the corresponding $\rho$, this price vector yields a maximum to $W(U, x \mid \rho)$. 
In the second part of the scheme, the observer sends each household a copy of the table, and each household calculates its own level of welfare $\ln V_{k}$ at every price vector in the table. The household then returns a ballot on which it has recorded the value of $\rho$ for which the corresponding price yields a maximum to $\ln V_{k}$. Let this report be denoted $\rho_{k}^{*}$. In the final step the $K$-vector of $\rho_{k}^{*}$ 's is combined into a social choice, $\rho^{*}$. In this last step, the median value of the $\rho_{k}^{*}$ 's is announced as society's choice of aversion to inequality.

This scheme may be thought of as a constitutional convention for carrying out social policy. The social observer can be compared to a computer calculating, for any conceivable value of $\rho$, the price vector that maximizes $W(U, x \mid \rho)$ in $(10)$. The observer only needs to be given the appropriate $\rho$ parameter in order to choose the best policy. The parameter itself is voted upon by society, with each household casting a single ballot on which it has noted its preferred value for $\rho$. We suppose that the winning $\rho$ defeats all alternatives in a pairwise majority vote.

\section{The social observer's problem}

The social observer is free to consider setting prices however he chooses, so long as $p_{i}>0$ for each good $i$. Demands are homogeneous of degree zero in prices; it is assumed the prices are normalized by setting $p_{n}=1$. Then the set of prices that is available - the social observer's "choice set" - is $P=R_{++}^{n-1}$. The problem for the observer is to maximize $W(U, x \mid \rho)$ on $P$. Let $p^{*}(\rho)$ denote the solution to this problem:

$$
p^{*}(\rho)=\underset{p \in \mathcal{P}}{\operatorname{argmax}} W(U, x \mid \rho) .
$$

We assume that the observer's table is finite in length. That is, there is some finite $T$ sufficiently large that $\left|\rho^{*}\right|<T$. The search, then, will take place on the interval $[-T,-1]$. The maximization problem in Equation (13) is well defined only if $W$ is strictly concave in $p$ and achieves a unique maximum on $P$. Numerical evidence from our empirical analysis suggests that $W$ has this property. Let us suppose that the observer's problem does indeed have a unique solution for each $\rho{ }^{7}$

\subsection{THE HOUSEHOLDS' PROBLEM}

Upon inserting $p^{*}(\rho)$ into its own money metric welfare function $\ln V_{k}$, household $k$ can calculate its welfare as a function of $\rho$. The household's problem is to calculate the value of $\rho$ at which its welfare level is maximized. Its informational resource $\Omega_{k}$ limits the household to responding to the observer's query with its preferred level for $\rho$. Let $\rho_{k}^{*}\left(U, x \mid \Omega_{k}\right)$ denote the solution to household $k$ 's problem.

$$
\rho_{k}^{*}\left(U, x \mid \Omega_{k}\right)=\underset{\rho_{k} \in[-T,-1]}{\operatorname{argmax}} \ln V_{k}\left(y_{k} / m_{0}, p^{*}(\rho), d_{k}\right) .
$$


Note that $\rho_{k}^{*}$ is a composite mapping that depends upon $\rho$ indirectly through $p^{*}(\rho)$.

Because $\ln V_{k}$ is a continuous function defined on a closed set, it must achieve a maximum on $[-T,-1]$. If $\rho_{k}^{*}$ achieves a maximum over an interval - if there are multiple values of $\rho$ that yield the same level of welfare - then we assume that the household selects the one with the smallest absolute value. ${ }^{8}$

\subsection{THE VOTING-FOR-EQUITY SCHEME}

Our scheme for deducing society's collective opinion concerning the level of equity that should be incorporated in policy making - the choice of $\rho$-involves compiling the individual $\rho_{k}^{*}$ into a single value $\rho^{*}$. For this purpose we assume majority rule, with households now playing the role of voters.

Consider the $K$-vector $\left(\rho_{1}^{*}, \ldots, \rho_{K}^{*}\right)$ of optimal $\rho$ 's. We assume that in any pairwise vote, each of the non-interactive households naively selects the value for $\rho$ that is nearest to $\rho_{k}^{*}$ according to the Euclidean distance metric. Given this assumption, Black's [11] median voter theorem guarantees that the median of the $\rho_{k}^{*}$ 's will be a majority rule winner. Denote this median by $\rho^{*}$.

Define a voting for equity scheme $S$ as the algorithm of the proposed voting mechanism, where voters maximize their individual money metric welfare functions $\left(\ln V_{1}, \ldots, \ln V_{K}\right)$ and the observer maximizes the social welfare function $W$. We now provide a definition for a solution for $S$. This definition requires simply that households choose optimally, that the majority rule winner is selected as society's optimal $\rho$, and that given this value the social observer selects a price vector according to (13). ${ }^{9}$

DEFINITION. Given a voting for equity scheme $S$, a solution is a pair $\left(\rho^{*}, p^{*}\right)$ at which (i) households choose $\rho_{k}^{*}$ according to (14) and $\rho^{*}$ is the median of the $\rho_{k}^{*}$, and (ii) $p^{*}$ solves (13) given $\rho^{*}$.

\section{The dataset}

This section reports information concerning the data from twelve different expenditure surveys conducted by the Italian National Institute of Statistics from 1985 to 1996. The samples are composed of about 30,000 households. The surveys are representative of the Italian population. Expenditures were collected during weekly interviews using the "booklet method" with recall. After general checks for consistency, 22,740 households were selected for the years from 1989 to 1995 and 19,581 households in 1996. Goods were aggregated into three large categories expressed as expenditure shares: food, including food consumed away from home (FOODSH), education (EDUSH), and all other goods (OTHSH) such as housing, health, clothing for adults, clothing for children, energy and transportation. This high level of aggregation was chosen with the aim of enhancing our ability to control the social welfare experiment. We selected 12 demographic variables. They 
Table II. Summary statistics of variables - selected years

\begin{tabular}{|c|c|c|c|c|c|c|c|c|}
\hline \multirow[t]{2}{*}{ Variables } & \multicolumn{4}{|c|}{1985} & \multicolumn{4}{|c|}{1996} \\
\hline & Mean & Std Dev & Min & Max & Mean & Std Dev & Min & Max \\
\hline Share of Food & 0.345 & 0.138 & 0.001 & 0.861 & 0.254 & 0.112 & 0.003 & 0.753 \\
\hline Share of Education & 0.056 & 0.063 & 0.000 & 0.851 & 0.064 & 0.062 & 0.000 & 0.791 \\
\hline Share of Other goods & 0.599 & 0.136 & 0.092 & 0.994 & 0.682 & 0.119 & 0.131 & 0.989 \\
\hline Log of Food price & 1.517 & 0.393 & 0.239 & 2.611 & 2.172 & 0.375 & 0.833 & 3.202 \\
\hline Log of Education price & -0.325 & 1.113 & -2.778 & 1.535 & 0.343 & 1.069 & -2.248 & 2.064 \\
\hline Log of Other goods price & 0.437 & 0.766 & -2.227 & 2.534 & 1.243 & 0.693 & -0.960 & 2.966 \\
\hline Child below 5 years & 0.199 & 0.494 & 0.000 & 6.000 & 0.162 & 0.442 & 0.000 & 4.000 \\
\hline Child above 5 and below 14 & 0.381 & 0.713 & 0.000 & 6.000 & 0.278 & 0.598 & 0.000 & 5.000 \\
\hline Child above 14 and below 18 & 0.206 & 0.484 & 0.000 & 5.000 & 0.155 & 0.409 & 0.000 & 5.000 \\
\hline Sex of Head - Female & 0.177 & 0.382 & 0.000 & 1.000 & 0.204 & 0.403 & 0.000 & 1.000 \\
\hline Head self employed & 0.195 & 0.396 & 0.000 & 1.000 & 0.185 & 0.388 & 0.000 & 1.000 \\
\hline Working wife & 0.259 & 0.438 & 0.000 & 1.000 & 0.308 & 0.462 & 0.000 & 1.000 \\
\hline Household living in rural areas & 0.060 & 0.238 & 0.000 & 1.000 & 0.054 & 0.225 & 0.000 & 1.000 \\
\hline Household living in North & 0.453 & 0.498 & 0.000 & 1.000 & 0.457 & 0.498 & 0.000 & 1.000 \\
\hline Household living in South & 0.336 & 0.472 & 0.000 & 1.000 & 0.330 & 0.470 & 0.000 & 1.000 \\
\hline Number of invalids & 0.026 & 0.172 & 0.000 & 4.000 & 0.018 & 0.138 & 0.000 & 3.000 \\
\hline Number of elderly & 0.346 & 0.631 & 0.000 & 6.000 & 0.373 & 0.653 & 0.000 & 5.000 \\
\hline Number of adults $(>18)$ & 1.863 & 1.101 & 0.000 & 8.000 & 1.911 & 1.175 & 0.000 & 8.000 \\
\hline Family size & 2.996 & 1.420 & 1.000 & 10.000 & 2.879 & 1.291 & 1.000 & 10.000 \\
\hline Log of expenditure & 14.102 & 0.678 & 11.272 & 16.961 & 14.915 & 0.580 & 12.596 & 17.436 \\
\hline Number of observations & \multicolumn{4}{|c|}{32458} & \multicolumn{4}{|c|}{19511} \\
\hline
\end{tabular}

include the number of children five years of age or less (NCH05), the number of children from 6 to 14 years of age (NCH614), the number of children from 15 to 18 years of age (NCH1518), the number of adults ( $>18$ years), and dummy variables for the presence of a women as head of the household (SEX_F), of a selfemployed head of the household (L_IND), of a working wife (TS), of a household located in a rural area, of a household located in the North of Italy (R1), of a household located in the South of Italy (R3), of a household with at least one invalid component (INVALIDS), and of a household with at least one elderly component (NANZ). Prices were obtained using the methodology developed by Lewbel [34] and described in Atella, Menon and Perali [6].

Table II contains summary statistics, for selected years, of the shares, log prices, log of total expenditure (LNXH) and demographic variables included in the model. As we can observe, households' consumption behaviour changed across the period of investigation, as did socio-demographic characteristics. The share of food con- 
sumption decreased from about 35 percent in 1985 to 25.4 percent in 1996. The education share increased slightly, while the share of other goods increased in order to compensate the change in food consumption. In terms of socio-demographic characteristics, we note that the number of children below 18 years has decreased significantly (especially in the age band from 5 to 14 years), indicating a decrease in the fertility rate of Italian households. At the same time the number of adults ( $>18$ years) remained almost constant, while the average family size has decreased slightly. The number of households with a female head has increased ( 0.17 in 1985 vs. 0.20 in 1996) as well as the number of households with a working spouse (from 0.26 in 1985 to 0.31 in 1996). The number of households living in rural areas decreased steadily up to 1996 . The number of household members with physical limitations decreased. In line with the progressive aging of the population, the number of elderly increased.

\section{The empirical analysis}

The estimation of the Barten demographically modified linear-in-log-y AIDS model maximizes a concentrated likelihood function of the joint system of Food, Education and Other Goods shares. The system has been estimated imposing the theoretical requirements of symmetry and homogeneity, and the IB requirements for cardinal comparability [34] as maintained hypotheses.

\subsection{ECONOMETRIC RESULTS}

Convergence of the models was obtained in few iterations, despite the high nonlinearity of the model and the relatively high number of socio-demographic variables included. ${ }^{10}$

Individual preferences must be well-behaved in order to be aggregated into a plausible social welfare function. The estimated uncompensated, compensated price and expenditure elasticities are reported in Table III for selected years. The signs of the own-price effects conform with the Slutsky requirements at the data means. Concavity, as verified by computing eigenvalues at each observation, is maintained over a large region of the data for most years. This behavioural requirement is of special importance in the present study. In fact, concavity of the individual welfare functions is necessary for concavity of the social welfare function and thus the estimated demand system can reasonably be used to carry out welfare analysis.

The signs and magnitudes of the own and cross-price elasticities (compensated and uncompensated), reported in the second and third panel of Table III, are reasonable, significantly different from zero and in line with those estimated for other studies. The cross-price effects are sign consistent, as required, and show both substitution and complementarity effects, with the exception of the compensated elasticities in 1996 that present only substitution effects. The expenditure elas- 
Table III. Income and price elasticities ${ }^{(*)}$

\begin{tabular}{|c|c|c|c|c|c|}
\hline \multicolumn{6}{|c|}{ Income elasticities } \\
\hline & 1985 & 1989 & 1992 & 1994 & 1996 \\
\hline Food & 0.888 & 0.841 & 0.912 & 0.923 & 0.940 \\
\hline Education & 1.228 & 1.228 & 1.228 & 1.186 & 1.228 \\
\hline Other & 1.040 & 1.040 & 1.040 & 1.013 & 1.040 \\
\hline \multicolumn{6}{|c|}{ Uncompensated price elasticities } \\
\hline & 1985 & 1989 & 1992 & 1994 & 1996 \\
\hline$\varepsilon_{\mathrm{pf}, \mathrm{pf}}$ & -0.389 & -0.332 & -0.384 & -0.363 & -0.412 \\
\hline$\varepsilon_{\mathrm{pe}, \mathrm{pf}}$ & 0.028 & 0.141 & 0.106 & 0.054 & 0.110 \\
\hline$\varepsilon_{\text {po,pf }}$ & -0.338 & -0.326 & -0.245 & -0.258 & -0.228 \\
\hline$\varepsilon_{\text {pf,pe }}$ & 0.025 & 0.040 & 0.041 & 0.029 & 0.043 \\
\hline$\varepsilon_{\text {pe,pe }}$ & -0.229 & -0.347 & -0.420 & -0.487 & -0.492 \\
\hline$\varepsilon_{\text {po,pe }}$ & -0.087 & -0.081 & -0.069 & -0.060 & -0.064 \\
\hline$\varepsilon_{\text {pf,po }}$ & -0.524 & -0.549 & -0.569 & -0.590 & -0.571 \\
\hline$\varepsilon_{\text {pe,po }}$ & -1.027 & -0.818 & -0.838 & -0.753 & -0.799 \\
\hline$\varepsilon_{\text {po, po }}$ & -0.615 & -0.665 & -0.706 & -0.695 & -0.714 \\
\hline \multicolumn{6}{|c|}{ Compensated price elasticities } \\
\hline & 1985 & 1989 & 1992 & 1994 & 1996 \\
\hline$\varepsilon_{\mathrm{pf}, \mathrm{pf}}$ & -0.093 & -0.081 & -0.148 & -0.117 & -0.175 \\
\hline$\varepsilon_{\mathrm{pe}, \mathrm{pf}}$ & 0.437 & 0.447 & 0.404 & 0.370 & 0.408 \\
\hline$\varepsilon_{\text {po,pf }}$ & 0.009 & -0.005 & 0.019 & 0.012 & 0.026 \\
\hline$\varepsilon_{\mathrm{pf}, \mathrm{pe}}$ & 0.076 & 0.092 & 0.098 & 0.088 & 0.104 \\
\hline$\varepsilon_{\text {pe,pe }}$ & -0.158 & -0.285 & -0.348 & -0.412 & -0.417 \\
\hline$\varepsilon_{\text {po,pe }}$ & -0.027 & -0.016 & -0.005 & 0.004 & $0.001^{\mathrm{a}}$ \\
\hline$\varepsilon_{\text {pf,po }}$ & 0.017 & -0.011 & 0.050 & 0.029 & 0.071 \\
\hline$\varepsilon_{\text {pe,po }}$ & -0.279 & -0.163 & -0.056 & 0.043 & $0.009^{\mathrm{a}}$ \\
\hline$\varepsilon_{\text {po,po }}$ & 0.018 & 0.021 & -0.014 & -0.016 & -0.027 \\
\hline
\end{tabular}

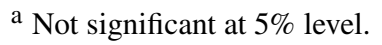

ticities for education and other goods remain fixed over the whole time period. However, food elasticities increase slightly over time.

The marginal effects of the demographic characteristics included in the model ${ }^{11}$ are in general significantly different from zero. Interestingly, the signs and magnitudes of these elasticities change across the years. This is in contrast with the results we have seen for income and price elasticities, thus indicating that the Barten specification captures the sample heterogeneity effectively. As expected, the presence 
of young children is positively related to food expenditure and negatively related to the education share. Over the years this effect increased. On average, expenditure on education is negatively related to the presence of very young children, while positively related to older children. This effect is maintained across the years. The presence of a self-employed head of household does not seem to lead to differences in terms of expenditure pattern. The presence of a working wife has a negative effect on food consumption and a positive effect on household expenditure on education. These results are quite reasonable, and in line with the values of the income elasticity of the education share, given that a working wife makes it possible to increase household income. Living in rural areas, on the other hand, has a positive effect on both food and education shares. Living in the North of Italy has a positive effect on food. Again, for those living in the North of Italy the elasticity of expenditure on education moves from negative values in the mid ' 80 s to high positive values at the end of our period of investigation. Invalids and the elderly have strong positive effects on food and negative effects on education. Similar results are found for the number of components in the household.

These results are in line with the general observed behavior and confirm the robustness of our approach in modelling household behavioural heterogeneity. As will be shown later, heterogeneity turns out to be an important factor in explaining households' voting behaviour.

\subsection{THE DEGREE OF AVERSION TO INEQUALITY IN ITALY}

As a further step to estimate the degree of aversion to inequality we have carried out the calculations of $p^{*}(\rho)$ (Equation (13)) and the $\rho_{k}^{*}$ (Equation (14)) numerically. We take values of $\rho$ in the interval from -1 to -10 , in increments of 0.1 . The solution to (14) is calculated for the 91 values of $\rho$ in this grid.

Inspection of the plots of the surfaces and of the level curves of the observer's objective functions $W$ for each year shows the location of the optimal price vectors, which is a global optimum. ${ }^{12}$ In Table IV, and just for 1996, we report the relationship between selected values of $\rho$ and the corresponding optimal prices. ${ }^{13}$ The difference between $\ln \bar{V}$ and $W$ in Equation (10) associated with the price policy scheme at each $\rho$ is the value of the equity term. When $\rho$ reaches -9 , the optimal policy ceases its movement. This is because at this level the equity term in (10) becomes negligible, and the observer's objective becomes the maximization of average welfare.

A household, being interested only in its own welfare, does not care about social welfare but only about the relationship between $\rho$ and its own $\ln V_{k}$. Using this fact, we solve each household's problem by calculating $\ln V_{k}$ for each $\rho$, using the corresponding price pair $\left(p_{1}, p_{2}\right)$. The $\rho$ corresponding to the maximum $\ln V_{k}$ is selected as the household's choice. It has been denoted $\rho_{k}$, and equals the value that household $k$ writes on the ballot in the voting-for-equity scheme. 
Table IV. Relationship between selected values of $\rho$ and optimal prices - 1996

\begin{tabular}{lllll}
\hline$\rho$ & $p_{1}(\rho)$ & $p_{2}(\rho)$ & $\ln \bar{V}$ & $W(U, x \mid \rho)$ \\
\hline-1 & 0.72894 & 1.40578 & -0.82908 & -0.83410 \\
-1.5 & 0.73489 & 1.40070 & -0.82905 & -0.82945 \\
-2 & 0.73520 & 1.40042 & -0.82905 & -0.82914 \\
-2.5 & 0.73524 & 1.40040 & -0.82905 & -0.82909 \\
-3 & 0.73525 & 1.40036 & -0.82905 & -0.82907 \\
-3.5 & 0.73527 & 1.40042 & -0.82905 & -0.82907 \\
-4 & 0.73525 & 1.40045 & -0.82905 & -0.82906 \\
-4.5 & 0.73527 & 1.40042 & -0.82905 & -0.82906 \\
-5 & 0.73524 & 1.40043 & -0.82905 & -0.82906 \\
-5.5 & 0.73526 & 1.40047 & -0.82905 & -0.82906 \\
-6 & 0.73526 & 1.40047 & -0.82905 & -0.82906 \\
-6.5 & 0.73524 & 1.40040 & -0.82905 & -0.82906 \\
-7 & 0.73525 & 1.40043 & -0.82905 & -0.82906 \\
-7.5 & 0.73524 & 1.40041 & -0.82905 & -0.82906 \\
-8 & 0.73525 & 1.40044 & -0.82905 & -0.82906 \\
-8.5 & 0.73523 & 1.40040 & -0.82905 & -0.82906 \\
-9 & 0.73525 & 1.40038 & -0.82905 & -0.82906 \\
-9.5 & 0.73525 & 1.40043 & -0.82905 & -0.82906 \\
-10 & 0.73523 & 1.40042 & -0.82905 & -0.82906 \\
\hline
\end{tabular}

The distribution of households' votes for $\rho_{k}^{*}$ is presented in Figur 4 for each year of the period 1985-1996. In each year, the distributions are bimodal and suggestive of an insight by Downs [22] regarding the outcome of a social choice problem in a single dimension. The right density of the votes showing a preference towards less equity is, in general, more dispersed. Across the years, the polarization of the vote around "low" and "high" values has changed substantially. It is interesting to note that in 1996, the first year in which Italians have voted using a majoritarian electoral system, the degree of polarization reaches a maximum. The majority outcome for the twelve years of our surveys, as given by the median, is reported in Figure 5. These are the equity levels that society chooses in response to the optimal price policy. Although these values have not changed substantially across the period of investigation, the distribution of votes has, on the other hand, changed quite markedly.

This information provides some remarkable evidence. With the exception of the years 1990 and 1995, the share of households oriented towards equity is consistently above 50 percent and is quite stable. In contrast, the share of less equity oriented households is more variable, with the highest values (about 42 percent) 


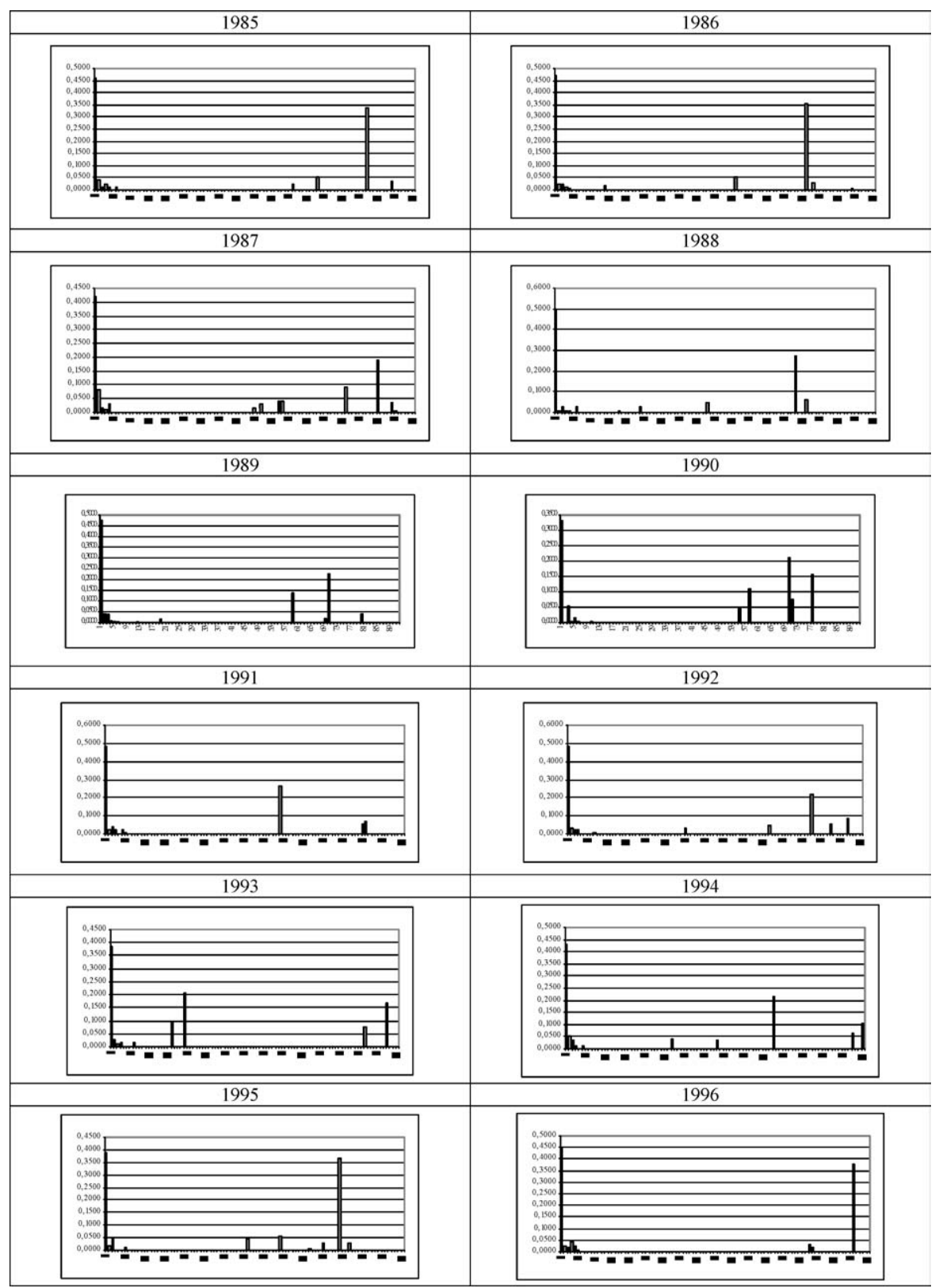

Figure 4. Distribution of household votes by year. 


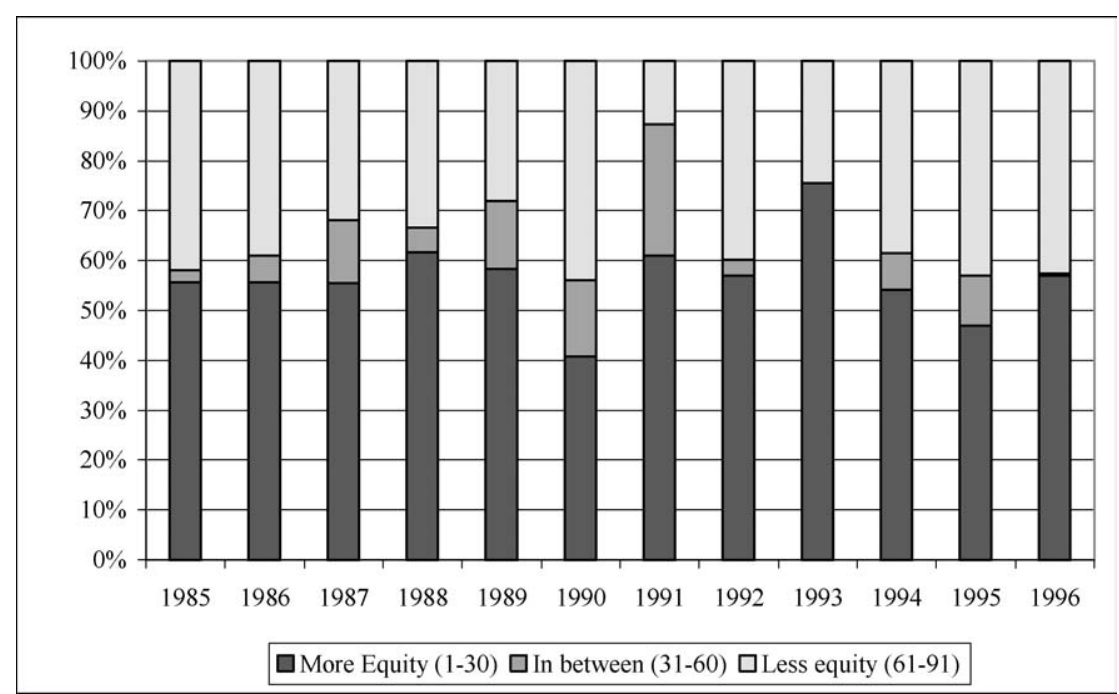

Figure 5. Distribution of votes by year.

reached in 1990, 1995 and 1996. The share of non-oriented households is rather small (with the exception of 1991) and whenever the share of less equity-oriented households increased, this reduced the share of non oriented households (except in 1990), rather than the share of less equity-oriented households. The 1993 distribution is particularly interesting. As already discussed in the second paragraph, the year 1993 represents both the year of the political break and the negative peak of one of the worst recession periods since the Second World War. It is also the year in which the rate of growth of permanent disposable income reaches its minimum (see Figure 3). It is then remarkable to observe that in 1993 we record the highest share of equity-oriented households (75 percent).

With the aim of learning something about the relative importance of the level of household income in determining the voting outcome, we conduct the experiment of running elections for specific segments of the population partitioned in income quintiles choosing the 1996 population as our reference. In general, poor households are associated with a higher preference towards equity than more affluent households. As shown in Figure 6, the outcomes are collapsed into three classes according to the following classification: more equity-oriented households $(-1 \leq \rho \leq-30)$, equity-uncertain households $(-31 \leq \rho \leq-60)$, and less equity-oriented households $(-61 \leq \rho \leq 91)$. The results are reported for the whole population, for the first and second decile (the first quintile), the second, third and fourth quintile, and for the ninth and tenth decile. Inspection of Figure 6 reveals that the number of households that presents a higher degree of aversion to inequality decreases moving from the first to the tenth decile. In the first decile, about 75 percent of the households presents a high degree of aversion to inequality. This value drops to 47 percent in the ninth decile and to 51 percent in the 


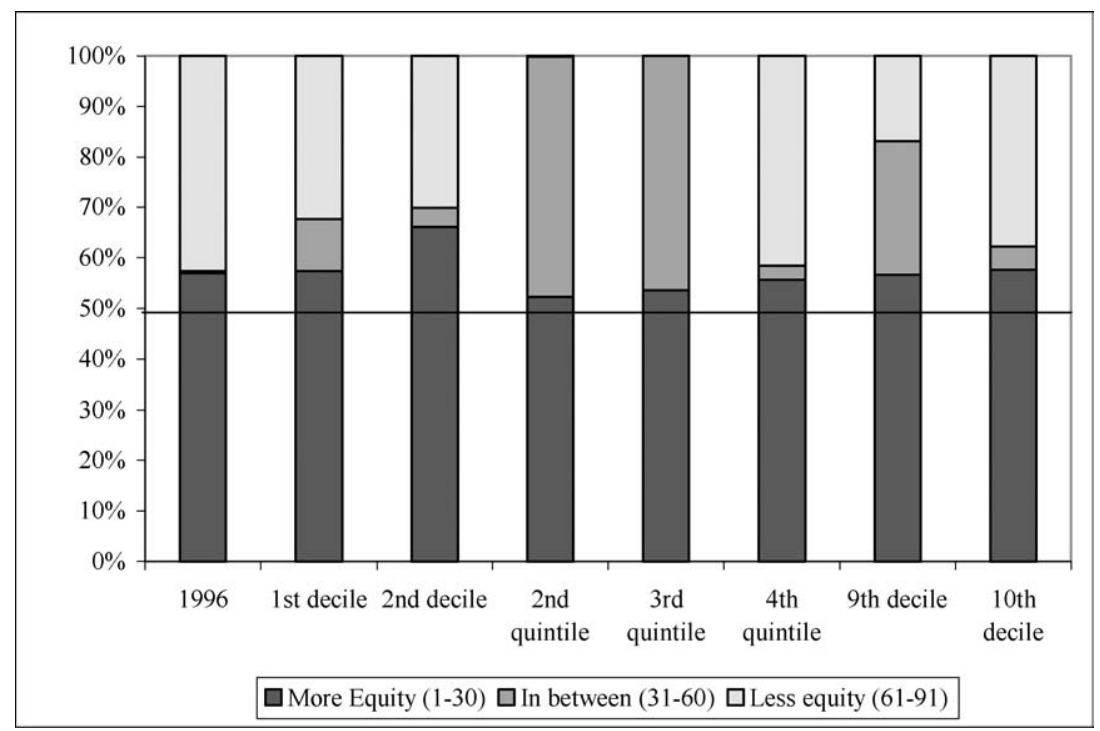

Figure 6. Voting by deciles and quintiles of income - Year 1996.

tenth decile. Contemporaneously, the share of households that prefer inequality increases across deciles. In the second and third quintile the share of uncertain voters dominate the voters giving less importance to equity.

For the reference year 1996, the distribution of votes by income quintile is as follow. In the first quintile, about 70 percent of the population is more concerned for equity. This proportion decreases monotonically but at a decreasing rate moving towards the higher quintile where the proportion is about 49 percent.

\section{Determinants of the attitudes towards inequality}

Another interesting aspect of the empirical analysis is to explore the links existing between the households' choice of the degree of aversion to inequality and their socio-demographic characteristics. The literature on the determinants of "attitudes towards inequality" is vast. Different theories have been presented to explain differential preferences about inequality. According to Shurcke [49], ${ }^{14}$ the following is the list of the main determinants that have been explored in the literature: individuals' current income [41, 36], individuals' expected future income [27, 10], individuals' mobility experience [1], perception of determinants of income generation ("achievements" vs. "ascription") [19], and perception of actual income inequality in society [2]. Apart from the work by Shurcke [49], we are not aware of empirical studies which have verified such assumptions jointly.

While our dataset enables us to test the hypotheses of individuals' current income $[41,36]$, and individual's expected future income $[27,10]$ as proxied by the level of education of the household head, we can study how preferences vary across 
Table V. Determinants of $\rho^{*}-$ Pooled dataset

\begin{tabular}{|c|c|c|c|c|}
\hline \multirow[t]{2}{*}{ Dep. Var. $=$ class of $\rho$} & \multicolumn{4}{|c|}{ Ordered probit model 1} \\
\hline & $\theta F / \theta x$ & Coef. & $z$ & $P>|z|$ \\
\hline Child 0-5 & 0.1367 & 0.2688 & 44.11 & 0.00 \\
\hline Child 6-14 & 0.1600 & 0.3133 & 71.43 & 0.00 \\
\hline Child 15-18 & 0.2747 & 0.5530 & 86.92 & 0.00 \\
\hline Sex head of household ( 1 if male, 2 if female) & 0.1005 & 0.3305 & 46.28 & 0.00 \\
\hline Self employed & 0.0052 & 0.0202 & 3.74 & 0.00 \\
\hline Working wife & -0.1881 & -0.4119 & -80.32 & 0.00 \\
\hline Living in rural areas & 0.0035 & -0.0045 & -0.54 & 0.59 \\
\hline Number of elderly & 0.1165 & 0.2513 & 29.57 & 0.00 \\
\hline Age of head of household & 0.0111 & 0.0261 & 23.49 & 0.00 \\
\hline Age squared of head of household & -0.0001 & -0.0002 & -18.20 & 0.00 \\
\hline North-West & -0.1491 & -0.4145 & -70.79 & 0.00 \\
\hline North-East & -0.1279 & -0.3543 & -58.33 & 0.00 \\
\hline Center & -0.0710 & -0.1445 & -23.92 & 0.00 \\
\hline South and Island & -0.0810 & -0.1477 & -16.19 & 0.00 \\
\hline Single under 65 & -0.0244 & -0.0908 & -5.86 & 0.00 \\
\hline Single over 65 & -0.1315 & -0.3677 & -20.42 & 0.00 \\
\hline Couple 0-65 & -0.0076 & -0.0341 & -2.38 & 0.02 \\
\hline Couple 65 and over & 0.3202 & 0.6195 & 28.69 & 0.00 \\
\hline One generation household $18-65$ & 0.3730 & 0.8274 & 67.78 & 0.00 \\
\hline Two generation household 0-65 & -0.3532 & -0.7584 & -78.54 & 0.00 \\
\hline Two generation household 18 - over & -0.0011 & 0.0068 & 0.50 & 0.62 \\
\hline Three generation household & 0.2038 & 0.3291 & 20.29 & 0.00 \\
\hline Owner of a boat & -0.0061 & -0.0115 & -0.99 & 0.32 \\
\hline Owner of house & -0.0024 & -0.0007 & -0.14 & 0.89 \\
\hline Log of net income & 0.0440 & 0.0987 & 25.09 & 0.00 \\
\hline Head of household education & -0.0136 & -0.0309 & -13.83 & 0.00 \\
\hline Year_85* & -0.1193 & 0.0632 & 4.56 & 0.00 \\
\hline Year_86* & -0.1210 & 0.0877 & 5.14 & 0.00 \\
\hline Year_87* & -0.1227 & -0.0371 & -2.15 & 0.03 \\
\hline Year_88* & -0.1663 & -0.5415 & -32.51 & 0.00 \\
\hline Year_89* & -0.1630 & -0.5621 & -34.83 & 0.00 \\
\hline Year_90* & 0.0557 & 0.0322 & 1.93 & 0.05 \\
\hline Year_91* & -0.1965 & -0.4944 & -33.25 & 0.00 \\
\hline Year_92* & -0.1429 & -0.0100 & -0.82 & 0.41 \\
\hline Year_94* & -0.1102 & -0.2617 & -22.05 & 0.00 \\
\hline Year_95* & -0.0291 & 0.2899 & 19.82 & 0.00 \\
\hline Year_96* & -0.1449 & 0.1151 & 8.24 & 0.00 \\
\hline Household level of confidence & 0.0008 & 0.0018 & 3.37 & 0.00 \\
\hline
\end{tabular}

$\rho^{*}$ goes from higher $(-1)$ to lower $(-90)$ concern for equity. 
different household demographic profiles. In other words, we aim at understanding how preferences towards equity differ between poor and rich households, households with many and few children, large and small households, households located in the North and in the South.

In order to shed light on this relationship, we use an ordered probit model to regress the vector of $\rho_{k}^{*}$ on households' characteristics and total expenditure, using robust standard errors to account for the presence of heteroskedasticity. As dependent variable we have used a categorical variable generated according to the following classification: 1 if more equity-oriented $(-1 \leq \rho \leq-20), 2$ if undecided $(-21 \leq \rho \leq-70)$, and 3 if less equity-oriented $(-71 \leq \rho \leq 91) .{ }^{15}$

From the econometric point of view we have approached the problem using a "year-by-year" estimation strategy and a "pooled" fixed-effect estimation strategy in which we have included time dummies for the 12 years and a variable that takes into account the level of household confidence over the period of investigation, thus representing another fixed effect.

The "pooled" results are reported in Table V. Inspection of Table V shows that, overall, equity matters more for households that have lower incomes, higher levels of education, are relatively older, include a working wife, or are headed by mothers living alone. In terms of generational composition, singles, elderly singles, couples from 18 to 65 years and couples with children seem to care more for equity than elderly couples and three-generation households. The business cycle, measured as an index of the level of household confidence, is another important variable that drives the vote towards a lower concern for equity when confidence is high. Interestingly, if we assume that education is a reasonable proxy for expected future income, our results show that individual's current income is more important than individual's expected future income in determining his/her attitude towards inequality.

\section{Conclusions}

The main goal of the paper has been to estimate the preferences of Italian society towards equity in order (i) to measure the degree of aversion towards inequality in Italian society and (ii) to verify whether preferences have changed across the years. Introducing equity concerns in the implementation of economic policies is a fundamental problem faced by both economists and policy makers. The paper uses a social welfare function, à la Jorgenson and Slesnick, to estimate society's aversion towards inequality by implementing a voting scheme for compiling individuals' equity preferences into a social choice by majority rule. The social welfare function has been estimated from ISTAT household budget data accounting for household heterogeneity and imposing the property of independence of the base level of utility chosen for welfare comparisons as required by full cardinal comparability. The social welfare function expressed in terms of prices, income and a chosen degree of aversion to inequality is then maximized for the optimal set of prices associated with sequential values for the aversion coefficient. Our incentive compatible voting 
mechanism asks households to "vote" for the set of prices which would maximise their individual welfare, thus revealing the "single peaked" individual preferences towards equity associated with the best prices. Society's aversion to inequality is that of the median voter.

Can the values for $\rho_{k}^{*}$ that we have obtained legitimately be called households' equity preferences? We believe that they can. It is true that households in our model have no concern for the welfare of others. People are interested only in themselves, and their preferred level of equity yields the greatest personal welfare. We deem that this is an interesting way to view individual equity preferences. In a democratic society an entirely separate rule, such as the majority rule that we employ, should be used to extract collective equity preferences from a profile of individual preferences. Without doubt, it is admissible that individual concerns for equity can also result from altruistic impulses, but in our view one of the virtues of our approach is that we are able to produce a collective concern for equity while retaining the utility-optimising framework for households.

In line with Coggins and Perali [18], our empirical results for the Italian case confirm that preferences are polarized around a low and a high degree of aversion to inequality and show that preferences changed over the years and were affected by the performance of the Italian economy. This effect was particularly visible in 1993, a year of sharp recession. Overall, equity matters more for households that have lower incomes, higher levels of education, are relatively older, include a working wife, or are headed by mothers living alone. In terms of generational composition, singles, elderly singles, couples from 18 to 65 years and couples with children seem to care more for equity than elderly couples and three generationhouseholds. The business cycle, measured as an index of the level of household confidence, is another important variable making the public less concerned about equity when the confidence in the economy is high.

\section{Notes}

${ }^{1}$ While it is rare in many democracies for all potential voters to exercise their voting right on any given election, in our model all households vote. Sen [47] argues that when the goal is a measure of social welfare, actual voting should not be relied upon both because not all citizens vote and because voting simply conveys too little information regarding interpersonal comparisons of well-being. Our hypothetical voting scheme seems to follow Sen's advice, except that for us each single household constitutes a voter.

2 The headcount ratios have been computed by the authors using the income surveys of the Bank of Italy, while the Gini coefficients are based on ISTAT (National Institute of Statistics) household budget surveys.

${ }^{3}$ Disposable income is defined as the difference between all incoming (wage, salaries, rents, transfers, etc.) and outcoming (taxes) financial flows occurring in a household in a year. Permanent disposable income is obtained as the long run component of disposable income obtained from the application of the Hodrey-Prescott filter.

${ }^{4}$ That is, $C$ must be homogenous of degree one in prices, nonnegative, nondecreasing in prices, increasing in $u$, increasing in at least one price, and concave. See Lewbel [33, Theorems 1-3]. 
${ }^{5}$ Lewbel [34] shows that the ability to write the cost function in this way is necessary and sufficient for a "cost of characteristics" index, $I_{k}=C\left(u ; p ; d_{k}\right)=C\left(U ; p ; d^{0}\right)$ to be IB, where $d^{0}$ is the demographic make-up of a reference household. If and only if the index is IB, an IB household scale exists.

${ }^{6}$ Lewbel [34, p. 383] also provides a useful discussion of the various degrees of comparability with cardinal and with ordinal preferences. The CFC property is built into Equation (4.4) in Jorgenson [28], upon whose social welfare function we rely in the next section. Note, though, that his underlying translog demand system is different from our AIDS framework.

${ }^{7}$ Note that this definition does not require market-clearing. One may think of the economy as moving toward a Walrasian equilibrium under the price policy, employing a rationing scheme to account for the temporary divergence between supply and demand. See Benassy [9] or Gardner [24].

${ }^{8}$ In the application presented in the following section, there are many households for whom there are multiple solutions to problem (14). Under our assumption that such a household chooses as its optimal $\rho_{k}$ the minimum of (the absolute value of) these values, its problem may be written $\rho_{k}^{*}(U ; x \mid \rho)=\max \left[\operatorname{argmax}_{\rho_{k} \in[-T,-1]} \ln V_{k}\right]$.

${ }^{9}$ Given our informational assumption - that households do not know other households' $\ln V_{k}-$ there is no scope here for strategic behavior. However, in future work the informational assumption we adopt here will be relaxed, permitting an exploration of the incentives facing households in the voting scheme and of the effects of strategic opportunities.

10 The values of the estimated demand parameters may be obtained upon request from the authors.

11 The values of the estimated marginal effects may be obtained upon request from the authors.

12 Surface and level curve plots have been obtained for the case with $\rho=-1$, as they depend upon $p_{1}$ and $p_{2}$. They are available upon request from the authors.

13 As already mentioned in the previous sections, we have chosen the childless couple as our reference household, and have calculated the vector of $m_{0}$ fixing the unit values at the reference household level.

14 The interested reader may refer to this paper for a more adequate description of such theories.

15 We have also explored a probit model where the dependent variable is a dichotomous variable equal to 0 when the value of $\rho_{k}^{*}$ is in the range $[0,-20]$ (more equity-oriented households), and 1 otherwise (non-oriented and less equity-oriented households), and an ordered probit model with a different grouping of $\rho_{k}^{*}$, namely 1 if equity-oriented household $(-1 \leq \rho \leq-30)$, 2 if undecided $(-31 \leq \rho \leq-60)$, and 3 if non equity-oriented household $(-61 \leq \rho \leq-91)$. The results do not show relevant differences and are therefore omitted here. They are available upon request.

\section{References}

1. Alesina, A. and La Ferrara, E.: Preferences for redistribution in the land of opportunities, NBER Working Paper No. 8267, 2001

2. Alesina, A., Di Tella, R. and MacCulloch, R.: Inequality and happiness: Are Europeans and Americans different?, NBER Working Paper No. 8198, 2001.

3. Amiel, Y., Creedy, J. and Hurn, S.: Measuring attitudes towards inequality, Scandinavian Journal of Economics 101 (1999), 83-96.

4. Arrow, K.: Social Choice and Individual Values, 2nd edn, Yale University Press, New Haven, 1963.

5. Atella, V.: Quinto Rapporto CNEL sulla Distribuzione e Redistribuzione del Reddito in Italia e in Europa 1998-1999, Documenti CNEL, Roma, 2000.

6. Atella V., Menon, M. and Perali, F.: Estimation of unit values in cross sections without quantity information and implications for demand and welfare analysis, In: C. Dagum and G. 
Ferrari (eds.), Household Behavior, Equivalence Scales, Welfare and Poverty, Physica-Verlag, Heidelberg, 2003.

7. Atkinson, A.B., Lee, R. and Smeeding, T.: Income distribution in european countries, In: A. Atkinson (ed.), Incomes and the Welfare State: Essays on Britain and Europe, Cambridge University Press, Cambridge, 1995.

8. Barten, A.P.: Family composition, prices, and expenditure patterns, In: P. Hart, L. Mills and J.K. Whitaker (eds.), Econometric Analysis for National Economic Planning, Butterworth Publishing, London, 1964.

9. Benassy, J.-P.: Developments in non-walrasian economics and the microeconomic foundations of macroeconomics, In: W. Hildenbrand (ed.), Advances in Economic Theory, Cambridge University Press, Cambridge, 1982.

10. Bénabou, R. and Ok, E.: Social mobility and the demand for redistribution: The POUM hypothesis, Quarterly Journal of Economics 116 (2001), 447-487.

11. Black, D.: On the rationale of group decision making, Journal of Political Economy $\mathbf{5 6}$ (1948), 23-34.

12. Blackorby, C., Boyce, R. and Russell, R.: Estimation of demand systems generated by the Gorman polar form: A generalization of the S-branch utility tree, Econometrica 46 (1978), 345-363.

13. Blackorby, C. and Donaldson, D.: Money metric utility: A harmless normalization?, Journal of Economic Theory 46 (1988), 120-129.

14. Blackorby, C. and Donaldson, D.: Adult-equivalence scales, interpersonal comparisons of wellbeing, and applied welfare economics, In: J. Elster and J.E. Roemer (eds.), Interpersonal Comparisons of Well-Being, Cambridge University Press, Cambridge, 1991.

15. Blundell, R. and Lewbel, A.: The information content of equivalence scales, Journal of Econometrics 50 (1991), 1-19.

16. Buccola, S.T. and Sukume, C.: Social welfare of alternative controlled-price policies, Review of Economics and Statistics 75 (1993), 86-96.

17. Christiansen, V. and Jensen, E.S.: Implicit social preferences in the norwegian system of social preferences, Journal of Public Economics 10 (1978), 217-245.

18. Coggins, J. and Perali, F.: Voting for equity: Estimating society's preferences toward inequality, Mimeo, University of Verona, 2002.

19. Corneo, J. and Grüner, H.P.: Individual preferences for political redistribution, Journal of Public Economics, 2000.

20. D'Aspremont, C. and Gevers, L.: Equity and the informational basis of collective choice, Review of Economic Studies 44 (1977), 199-209.

21. Deaton, A.S. and Muellbauer, J.: An almost ideal demand system, American Economic Review 70 (1980), 312-326.

22. Downs, A.: An Economic Theory of Democracy, Harper and Row Publishers, Inc., New York, 1957.

23. Fritzell, J.: Still different? Income distribution in the nordic countries in a european comparison, Luxembourg Income Study Working Paper No. 238, 1994.

24. Gardner, R.: $\lambda$-transfer value and fixed-price equilibrium in two-sided markets, In: P.K. Pattanaik and M. Salles (eds.), Social Choice and Welfare, North-Holland, Amsterdam, 1983.

25. Gorman, W.M.: Tricks with utility functions, In: M.M. Artis and A.R. Nobay (eds.), Essays in Economic Analysis: Proceedings of the 1975 AUTE Conference, Cambridge University Press, Cambridge, 1976.

26. Hammond, P.J.: Interpersonal comparisons of utility: Why and how they are and should be made, In: J. Elster and J.E. Roemer (eds.), Interpersonal Comparisons of Well-Being, Cambridge University Press, Cambridge, 1991. 
27. Hirschman, A.O.: The changing tolerance for income inequality in the course of economic development, with a mathematical appendix by Michael Rothschild, Quarterly Journal of Economics 87 (1973), 544-566.

28. Jorgenson, D.W.: Aggregate consumer behavior and the measurement of social welfare, Econometrica 58 (1990), 1007-1037.

29. Jorgenson, D.W.: Welfare - Measuring Social Welfare, MIT Press, Cambridge, 1997.

30. Jorgenson, D.W. and Slesnick, D.T.: Individual and social cost of living indices, In: W.E. Diewert and C. Montmarquetts (eds.), Price Level Measurement, Statistics Canada, Ottawa, 1983.

31. Jorgenson, D.W. and Slesnick, D.T.: Aggregate consumer behavior and household equivalence scales, Journal of Business and Economic Statistics 5 (1987), 219-232.

32. Jorgenson, D.W and Slesnick, D.: Inequality and the standard of living indexes, In: W.E. Diewert (ed.), Price Level Measurement, North-Holland, Amsterdam, 1990.

33. Lewbel, A.: A unified approach to incorporating demographic or other effects into demand systems, Review of Economic Studies 52 (1985), 1-18.

34. Lewbel, A.: Household equivalence scales and welfare comparisons, Journal of Public Economics 39 (1989), 377-391.

35. Lewbel, A.: Consumer demand system and household equivalence scales, In: M.H. Pesaran and P. Schmidt (eds.), Handobook of Applied Econometrics, Vol. II: Microeconomics, Blackwell Publishers, Cambridge, MA, 1997.

36. Meltzer, A. and Richards, S.: A rational theory of the size of government, Journal of Political Economy 89 (1981), 914-927.

37. Pollak, R.A. and Wales, T.J.: Demographic variables in demand analysis, Econometrica 49 (1981), 1533-1551.

38. Pollak, R.A. and Wales, T.J., Demand System Specification and Estimation, Oxford University Press, New York, 1992.

39. Roberts, K.W.S.: Interpersonal comparability and social choice theory, Review of Economic Studies 47 (1980), 421-439.

40. Roberts, K.W.S.: Possibility theorems with interpersonally comparable welfare levels, Review of Economic Studies 47 (1980), 409-420.

41. Romer, T.: Individual welfare, majority voting and the properties of a linear income tax, Journal of Public Economics 7 (1975), 163-188.

42. Rossi, N.: Secondo rapporto CNEL sulla distribuzione e redistribuzione del reddito in Italia 1993-1994, Il Mulino, Bologna, 1994.

43. Rossi, N.: Quarto rapporto CNEL sulla distribuzione e redistribuzione del reddito in Italia 1996-1997, Il Mulino, Bologna, 1998.

44. Sen, A.K.: Collective Choice and Social Welfare, Holden-Day, San Francisco, 1970.

45. Sen, A.K.: On Economic Inequality, Clarendon Press, Oxford, 1973.

46. Sen, A.K.: Personal utilities and public judgements: Or what's wrong with welfare economics, Economic Journal 89 (1979), 537-558.

47. Sen, A.K.: The possibility of social choice, American Economic Review 89 (1999), 349-378.

48. Slesnick, D.: Empirical approaches to the measurement of welfare, Journal of Economic Literature 36 (1998), 2108-2165.

49. Shurcke, M.: Preferences for inequality: East vs. West, Innocenti Working Paper No. 89, UNICEF Innocenti research Centre, Florence, 2001.

50. Stern, N.: Welfare weights and the elasticity of the marginal valuation of income, In: M. Artis and R. Nobay (eds.), Studies in Modern Economic Analysis, Basil Blackwell Publishers, Oxford, 1977. 